\title{
Assessing the explanatory power of naturalism in addressing ultimate questions ${ }^{\star}$
}

\section{J. Darvish Aghajani}

Sharif University of Technology,

Azadi Ave, Tehran, 11365-11155, Islamic Republic of Iran

For citation: Darvish Aghajani J. Assessing the explanatory power of naturalism in addressing ultimate questions. Vestnik of Saint Petersburg University. Philosophy and Conflict Studies, 2021, vol. 37, issue 2, pp. 217-228. https://doi.org/10.21638/spbu17.2021.203

A typical scientist has no responsibility other than to explain how a natural event occurred. However, when a philosopher asks about the conditions under which a scientist's explanation is true, he is, in fact, raising an ultimate question, the concept which Karl Popper used for the first time. Answering this question requires that no elements are neglected in the explanation, and no significant factors in the explanation are overlooked. In other words, in explaining a phenomenon, at any level of its explanation, there should be no remainder. These requirements can be achieved through the full explanation. In the present article, by drawing on concepts such as theory-ladenness of observation, underdetermination of theory by evidence, and the role of models and metaphors in developing a scientific theory, it is illustrated that a complete explanation includes both a scientific explanation and personal explanation. A personal explanation comprises mental properties such as belief, desire, and intention, which are irreducible to physical properties. Therefore, we cannot provide a personal explanation while restricting ourselves to scientific methods. Consequently, it is argued in this article first, the personal explanation is irreducible to a scientific explanation. Second, the personal explanation is inevitable in order to provide a full explanation. Third, (methodological) naturalists claim that the ultimate judgment of what is natural and unnatural is possible only by scientific inquiry. Finally, accepting these three premises entails the inability of a naturalist to answer ultimate questions.

Keywords: ultimate question, complete explanation, naturalism, personal explanation, reductionism.

\section{Introduction}

Nowadays, in academic circles and among researchers in philosophy, naturalism is no longer considered merely as a philosophical view along with other views. In fact, in all branches of philosophy, including philosophy of mind, philosophy of language, philosophy of ethics, etc., the naturalistic approach is regarded as a prevailing and relatively mainstream approach. Therefore, Kim's description of the status of naturalism in contemporary philosophy appears to be an accurate one when he refers to naturalism as "the Ideology

* I would like to express my deep gratitude to Professor Mikael Stenmark of Uppsala University, Sweden for his comments that significantly improved the manuscript. The earlier version of this article was presented at the "Research School in Philosophy of Religion", held jointly by Uppsala University and Lund University on 28-29 June 2018. Also, I am grateful to Professor Mehdi Golshani, Professor Seyyed Hassan Hosseini, and finally to the Mohajer Thinktank.

(C) St. Petersburg State University, 2021 
of the contemporary analytic philosophy" [1, p. 82]. To explain the relationship between naturalism and prominent philosophical movements of the earlier periods, such as materialism, Sellars considered materialism an ontological view versus mentalism, whereas naturalism is a cosmological position opposed to supernaturalism [2, p. 220-224].

Such claims attributed to contemporary naturalists indicate that naturalism encompasses a wide range of metaphysics that almost everything, including life, mind, language, ethics, aesthetics, and even religion, falls under its umbrella, and it seeks to present a fully naturalistic explanation of all of them ${ }^{1}$.

Nevertheless, this does not mean that naturalism has successfully provided a full explanation of all these fields. One of the challenges facing naturalists, which is examined in this article, is the ultimate questions. Perhaps, Karl Popper was the first person to refer to the concept of ultimate questions. At the first conference at Darwin College commemorating Darwin, he stated: "It is important to realize that science does not make assertions about ultimate questions - about the riddles of existence or about man's task in this world" [4, p. 342]. Later, these questions were mentioned in the scientific and philosophical literature under various titles. John Wheeler, a prominent American physicist and philosopher, introduced five questions as Really Big Questions (RBQ), including [5, p.xi]: "1 - How come existence? 2 - Why the quantum? 3 - A participatory universe? 4 - What makes meaning? 5 - Is information everything?" He raised these questions to reunite physics and metaphysics because modern science sought to explain the hows of the phenomena and was not concerned with the whys, which are mostly the concern of philosophy and theology. However, twentieth-century scientists and philosophers, such as John Wheeler, raised the questions concerning the 'whys' in their laboratories and classrooms [5, p.xi].

The main characteristic of the above questions is that they cannot be answered by peering through microscopes or conducting experiments even though they are related to science. In fact, these questions lay at the intersection of science and philosophy, and to further understand the world, science must answer them.

It is also essential to clarify the definition of naturalism assumed by the present article. According to Sellars' definition, naturalism claims that only natural things exist in reality. This is the ontological claim of naturalism. Besides this, there is also the methodological claim stating that the ultimate judgment of what is natural and unnatural is possible only by scientific inquiry. According to Kim's argument, the core of naturalism is something like this: "The scientific method is the only method of acquisition of authentic knowledge or information in all fields (including philosophy)" [1, p. 87]. This is the definition of (methodological) naturalism that is assumed in the present article.

According to the explanation provided of ultimate questions and the assumed definition of naturalism, the main argument of this article is that naturalism, due to the limitations of science's domain, does not have the explanatory capacity to deal with and answer ultimate questions. In other words, anyone who seeks to answer these questions within the framework of naturalism either basically has to ignore the questions or go beyond the realm of naturalism and violate the above definition.

To illustrate this point, the concept of full explanation has been used as the middle term of this article's main argument. After discussing the various ways naturalists deal with ultimate questions in the first section of the article, I will demonstrate that answering

${ }^{1}$ John Haught [3, p. 14] refers to representatives of naturalistic explanations of each of these concepts. 
these questions requires a full explanation, which will be the subject of the second part of the article. Finally, in the third section, I will argue that we inevitably have to provide personal explanations to achieve a full explanation. Personal explanations include one of the mental properties that are neither ruled by strict laws of science nor are reducible to physical properties. Hence, personal explanations are not reducible to scientific explanations, and consequently, naturalism fails to provide a full explanation or answer ultimate questions.

\section{How naturalism deals with ultimate questions}

Generally, to deal with and answer these questions, naturalists have employed three different approaches [6, p. 211-220]:

1. Ignoring ultimate questions (naturalistic anti-realism): some naturalistic philosophers believe that we cannot find answers to these questions or even understand the questions appropriately; therefore, we should ignore them completely. In contemporary analytic philosophy, this kind of view is known as eliminativism. Based on the history of science, eliminativists argue that many postulates in science that seemed to have an influential explanatory role were completely abandoned as science progressed. A typical example in this regard is ether ${ }^{2}$. Eliminativists in the philosophy of mind believe that mental properties and conscious states are ideas that belong to folk psychology. Today, since folk psychology has been replaced by neuroscience, folk psychology concepts have been abandoned and replaced with more precise scientific theories $[8$, p. 71,72$]$.

This view is anti-realistic about ultimate questions and the concepts pertinent to them, yet it strictly adheres to its naturalistic commitment. Therefore, it could be referred to as naturalistic anti-realism.

2. Attempts to answer ultimate questions applying modern science (naturalistic realism): many philosophers and scientists, while acknowledging these questions, do not go beyond naturalistic metaphysics and the scientific method to answer them. The method employed by most of them to deal with these questions is scientific reductionism. By definition, scientific reductionism means "that the results of inquiry in one domain [...] can be understood or are explained by the conceptual resources of another, more fundamental domain" [9, p. 696]. In naturalists' view, it is assumed that science is more fundamental than philosophy (or any other domain of human knowledge). An attempt is made to explain philosophical concepts based on scientific theories. I referred to this approach as naturalistic realism because neither of these questions are abandoned nor do we go beyond the realm of naturalism.

3. Going beyond the scientific method to answer ultimate questions (nonnaturalistic realism): the third approach to these questions is to use concepts, methods, and metaphysics found beyond modern science. In fact, those who advocate this approach have no choice but to expand their metaphysics in order

${ }^{2}$ In pre-twentieth century physicists' view, ether was a continuous material through which light rays and wave signals flowed. At the end of the nineteenth century, experiments were conducted that revealed flaws with the concept of ether and eventually in 1905, Einstein suggested that ether was a redundant concept $[7$, p. 4-6]. 
to answer ultimate questions. An example of this method is Putnam's explanation of the nature of sets, numbers, functions, and in general, mathematical facts. He introduced an idea known as indispensability arguments claiming that these facts are indispensable components of a physics theory (such as the law of gravity) and must be considered as real existence [10, p.53-56]. Since this approach takes a realistic stance on ultimate questions yet goes beyond the realm of naturalism, it is called non-naturalistic realism.

The above threefold categorization may be applied to all the concepts and issues challenging naturalism ${ }^{3}$. However, the argument presented in this article regarding ultimate questions concerning the characteristics mentioned in the previous section is specifically as follows: first, these questions cannot be denied within modern scientific discourse (objection of approach 1); and second, a naturalist is not permitted to expand his metaphysics in order to answer these questions (objection of approach 3 ).

Reviewing the first approach, which suggests completely ignoring these questions, it is necessary to reemphasize the definition and characteristics of ultimate questions. Answering ultimate questions sometimes have a direct effect on the process of scientific inquiry. For instance, a scientist's viewpoint of human nature (namely, physicalism, dualism, or panpsychism) affects his explanation of some human behaviors and properties, the most important of which is consciousness. For example, Sir John Eccles ${ }^{4}$ explains consciousness with a dualistic view and draws on Popper's three worlds as well as quantum mechanics ${ }^{5}$. In contrast to Eccles, the mainstream view in neuroscience and philosophy of mind is physicalism, wherein an attempt is made to explain consciousness physicalistically.

On the whole, eliminativism has few adherents in the philosophy of mind, even among physicalists. For instance, Jerry Fodor, as a physicalist, argues that folk psychology (which assumes the existence of belief, intention, and consciousness) sometimes can predict human behaviour much more advanced and accurately than neuroscience. Fodor gives the example in which his students can accurately predict that he would be at the university conference hall at 10 a.m. on Monday [13, p. 71]. This prediction capability and explanatory function do not allow us to ignore these concepts completely.

The third approach, that is, non-naturalistic realism to ultimate questions, leads to a contradiction. According to the definition of naturalism presented in the introduction, the only warranted method of acquiring authentic knowledge and the sole reliable source for judging what exists and what does not exist is a natural science. Accordingly, Kim concludes that accepting naturalism requires the acceptance of physical causal closure ${ }^{6}$ and explanatory closure. By explanatory closure, Kim means that no explanation of an event in the space-time world needs to invoke any phenomenon or agency outside the space-time world $[1$, p. 92, 93]. Therefore, accepting naturalism, we are not allowed to turn to abstract concepts such as mathematical facts or supernatural entities like God or the Hegelian

${ }^{3}$ The four main problems that challenge naturalistic explanation include morality, meaning, mind and modality, which are known as the four Ms [11, p. 247].

${ }^{4}$ Sir John Eccles (1903-1997), winner of the Nobel Prize in Neuroscience.

${ }^{5}$ In chapters 1 and 2 of his book How the Self Controls Its Brain, Eccles provides a detailed description of his view and how he reached it [12].

${ }^{6}$ Physical causal closure is defined as: "any physical event that has sufficient cause, has sufficient physical cause" $[14$, p. 178]. 
Absolute Spirit to explain natural phenomena. Thus, it is concluded that the third approach contradicts naturalism.

Discrediting options 1 and 3, the only approach left to a naturalist facing ultimate questions is the second option, which believes that science has sufficient explanatory power to answer ultimate questions. This approach has more supporters than the other two approaches. Theories proposed in various branches of science, such as Cosmology, Evolutionary Biology, and Data Sciences by the title of "Theory of Everything" (or similar titles), are related to this approach. However, I demonstrate that this path will eventually lead to option 1 or option 3. In fact, when we take the term "everything" in its literal sense in the Theory of Everything, then a naturalist will inevitably have to ignore some issues or go beyond naturalism to explain them. Therefore, in the following, first, it is shown that answering ultimate questions requires a complete explanation; then, it is argued that science does not have sufficient explanatory power to provide a complete explanation.

\section{Ultimate questions and a complete explanation}

The explanation is used to clarify why a particular situation exists. For instance, when we ask about the fluidity of the fluids or the greenness of the leaves, the sun's eclipse, or a genetic disease in a fetus, we do not really believe that these phenomena are necessary and needless to explain. The phenomenon which is to be explicated and requires elucidation is called the explanandum.

The explanation of an explanandum may involve several layers. For example, an explanandum such as 'free fall of a rigid body' is explained using Newton's law of universal gravitation. This law clearly shows why a rigid body falls down at a predictable rate. However, one may inquire about the nature of gravitational force itself as well as its origin. Here, Newton's law of gravitation itself is an explanandum. In the early 1900s, in seeking to answer this question, Einstein proposed his general theory of relativity and suggested that gravitational waves, which lead eventually some scientists and philosophers to the Big Bang theory, explain the cause of gravitational force. However, the question is whether Einstein's explanation is the ultimate one. Does this mean that it will leave no room for any further questions? The answer is no. It is still possible to ask why the Big Bang itself occurred, what happened before the Big Bang, and its causes. Therefore, the general theory of relativity is not a complete explanation either.

Richard Swinburne defines a complete explanation as follows:

"A complete explanation of the occurrence of $\mathrm{E}$ is a full explanation ${ }^{7}$ of its occurrence in which all the factors cited are such that there is no explanation (either full or partial) of their existence or operation in terms of factors operative at the time of their existence or operation" $[15$, p. 78$]$.

It means that in order to reach a complete explanation, in explaining the gravitational force in the above example when Newton's law of universal gravitation is used, the explanation itself should not contain any element that is an explanandum. However, this is not the case. Even when we moved one step back and discussed the general theory of relativity,

${ }^{7}$ Swinburne defines full explanation as follows: "If there is a full cause $\mathrm{C}$ for event $\mathrm{E}$ (a cause that is efficacious for the occurrence of E) and cause R that ensures the efficacy of $\mathrm{C}$, these conditions are what I should call 'full explanation' of the phenomenon E” [15, p. 24-25]. 
there is still some remainder. Thus, a complete explanation could be simply considered as an explanation that has "no further phenomena to be explained and the entities and properties postulated have a simplicity" [15, p. 87].

This interpretation of a complete explanation brings us closer to the definition and characteristics of the ultimate questions. While asking ultimate questions, we do not seek to explain a simple physical phenomenon. However, we ask about the fundamental conditions of the universe that have caused the phenomenon's occurrence. Ultimate questions, indeed, are the final or remaining questions in the explanation. Science has explained the phenomena and laws by scientific methods as far as possible, but in the end, some questions have not been answered by conventional methods. For example, when we ask about gravity law and then see the general theory of relativity, there are still questions such as 'how was the universe created and what was it created from?' which are ultimate questions about the explanation of gravity.

The fact that ultimate questions ask about the endpoint of an explanation indicates that in order to answer these questions, we need a complete explanation. This explanation is the endpoint and does not have any remainder.

\section{Incompleteness of naturalism in providing a complete explanation}

In the first section, we saw that the only sensible way of answering ultimate questions from a naturalistic perspective is to use the scientific method and scientific explanation and remain restricted within this framework. Therefore, considering the discussion in the previous section, we need to find out whether a scientific explanation can answer ultimate questions or, as explained in the previous section, whether it can provide a complete explanation. The answer to this question, according to the present article, is negative. The following argument presents the reason why naturalism is incapable of answering ultimate questions:

1. To answer ultimate questions, as well as to explain any phenomenon, naturalism has to stay within the limits of scientific explanation.

2. Complete explanation means reaching the endpoint of explanation where no elements remain unexplained.

3. There is always some personal explanation among the list of explanatory elements in a complete explanation of a phenomenon.

4. The personal explanation is not reducible to (or explainable by) scientific explanation.

5. The personal explanation is not compatible with naturalism.

6. Consequently, a complete explanation cannot be provided within the framework of naturalism.

In this argument, premise 1 was explained in the first section. It was clarified that, based on the definition of naturalism and explanatory closure, which Kim mentions as a critical characteristic of naturalism, to explain any issue, including the answer to ultimate questions, the only available tool is the scientific explanation. Premise 2 is also derived from the definition of complete explanation presented in the second section. However, premises 3 and 4 require further reasoning and more clarification, which is provided in the following section. 


\subsection{Complete explanation requires personal explanation}

In this section, some reasons are provided for premise 3. First, a few points regarding science and the scientific method should be mentioned. According to logical positivism, the scientific method was considered through the verification principle, which emphasized only observation and experimentation. Thus, statements that did not follow this method were considered meaningless. Eliminativism, which was discussed previously, is one of the implications of this approach. In fact, positivists sought to purify language from nonexperimental factors [16, p.22-23]. Nevertheless, considering the history of science and exploring the actual scientific theories revealed that a scientific theory is much more complicated than what the positivists assumed.

By taking a more profound look at observation, which is a critical factor in the scientific method, philosophers of science paid attention to the role of subjective elements. They argued that when scientists observe an objective phenomenon, they cannot be completely free of their own theories and subjective values; insofar as these theories sometimes affect observation. To provide an example, consider what is known as 'sunspots'. It is a phenomenon recognized by Chinese astronomers centuries ago. However, in Europe, due to the belief that heavenly bodies are immovable, this objective and variable terrestrial phenomenon was ignored until the Copernican revolution [17, p.112]. Such dependence of the observer on subjective values is labelled 'theory-ladenness of observation' by Thomas Kuhn ${ }^{8}$.

Moreover, philosophers of science turned away from the positivist's view resorting to the principle called 'underdetermination of theory by data.' According to this principle, there is more than one theory consistent with experimental evidence in most cases. Thus, choosing a theory requires something more than experimental evidence; it means that subjective factors are also involved [17, p. 162]. For example, underdetermination of theory by data could be applied to the geocentric Ptolemaic theory versus Copernicus's heliocentric theory. Regarding explanatory precision, both theories explained the location of the planets as well as the time of occurrence of solar and lunar eclipses with the same degree of accuracy, and non-experimental criteria were needed to choose one over the other.

In addition to the above two reasons, some philosophers of science have pointed out the undeniable role of metaphors in science, such as 'wavelength', 'electric field', 'black hole', etc., which fill the scientific language deficiency [18, p. 319]. Furthermore, some other philosophers of science have argued that models ${ }^{9}$ have a similar role in science. Models such as the 'plum pudding model' or 'particle-wave model of light' are concepts or frameworks used by scientists to interpret data and develop scientific theories. Models and metaphors are not objective entities in the world, but somewhat subjective conceptions formed by the human mind. Therefore, it should be considered that nature does not necessarily operate based on the models; instead, models are trapping parts of reality like fishing nets. Accordingly, the selection of the model is a decision made by a subject. The subject must choose from many models or curves that pass through countless recorded data and select

${ }^{8}$ After Thomas Kuhn, there was somehow a consensus among philosophers of science about this subject and the observer effect on the observation, but there is some disagreement as to how far this can be used in favour of scientific anti-realism. Realist philosophers of science believe that, in spite of this reality, the effect of theories on observations can be reduced by conducting more experiments and more and more diverse observers.

${ }^{9}$ Models may be considered as another form of metaphor in science. 
the one that best approximates reality and meets the criteria of simplicity, calculability, etc. ${ }^{10}$

In light of the abovementioned reasons, scrutinizing the scientific theory appears in at least three situations where the footprint of subjective factors can be found: 1) In observing and reporting experimental data (theory-ladenness); 2) In choosing among scientific theories (underdetermination); and 3) In interpreting experimental data and simplification of the behaviour of nature in order to make it understandable and theorize upon it (metaphors and models).

It is noteworthy that scientific anti-realists use subjective factors in a scientific theory as strong evidence to argue in their own favor $[19, \mathrm{p} .63]$. This issue in the debate between realists and anti-realists should be meticulously examined, but here we do not seek to argue in favor of anti-realism because when we talk about explaining a natural phenomenon such as an apple falling to the ground, physics provides its full explanation wherein subjective issues do not appear to disturb the accuracy and universality of the explanation. Models and metaphors, put to experimental test, constantly improve and approximate reality ${ }^{11}$. However, in all these cases, the main challenge is providing a complete explanation - not full explanation - which is the subject of this article. According to what was mentioned in the previous section, a complete explanation is a secondary explanation or an explanation of the explanation. Here, all the elements used in a full explanation must, in turn, be examined. It is in this second stage of explanation that subjective explanations are usually introduced. If a full explanation can explain and predict Perfect Gas's behaviour fairly well, it has done its job. In this case, actually, no questions remain about why and how this explanation is correct or where its curve comes from. However, for a complete explanation, all the elements and factors used in the explanation should not be left without explanation.

\subsection{Irreducibility of personal explanation}

This section is devoted to defending premise 4 . What is meant by personal explanation is that in explaining a phenomenon or an explanandum, we are concerned with the person's conscious action and why that motivates them to do so, instead of asking how the physical laws caused that phenomenon. Richard Swinburne states that in personal explanation, we provide an explanation based on the following components: "A person (S) with certain powers (P), beliefs (B) and purposes (G)" [21, p.3]. For instance, when we consider a murderer shooting a victim, the murderer $(S)$, who has a gun and the power to shoot $(\mathrm{P})$, does so with the purpose of killing the other person $(\mathrm{G})$ and believing that he deserves to die (B).

Due to its components (especially 'purpose' and 'belief'), the above definition distinguishes personal explanation from scientific explanation. Dennett ${ }^{12}$ distinguishes the personal and sub-personal levels of explanation, stating that "it is only on the personal level

${ }^{10}$ For example, consider the data obtained from the pressure change per volume at a constant temperature for a gas, which includes numerous points on a pressure-volume graph.

${ }^{11}$ Although there are issues, such as the measurement problem in quantum mechanics, which are considered by the mainstream physicists to be essentially indeterminate and inexplicable by natural causes $[20$, p. 56].

12 Daniel Dennett $(1942-\ldots)$, American Cognitive Scientist and naturalist philosopher of mind. 
that explanation proceeds in terms of the needs, desires, intentions, and beliefs of an actor in an environment" [22, p. 164].

Here, my argument is that personal explanation fundamentally differs from scientific explanation because of its different elements, purpose, and explanatory level. In personal explanation, as seen in the components mentioned in Swinburne's and Dennett's definitions, we deal with issues such as belief and desire, which are studied under the general title of 'mental properties' in the philosophy of mind. An essential characteristic of 'mental properties' is that they are not ruled by strict laws, such as laws of physics. This is Davidson's famous argument according to which, in physical causation, there is a principle stipulating that physical events are ruled by strict laws. For instance, the fall of a rigid body or electric current in a conductor can be explained by strict laws of physics. Therefore, it is stated that these phenomena have a nomological property. However, mental properties and mental phenomena do not possess this property. Strict laws do not rule our beliefs and intentions; they are governed by human rationality, and human rationality does not have a specific location in the brain. Hence, rationality cannot be measured or observed to explain or predict human behaviour [23, p. 122-124]. This distinction causes an unbridgeable gap between mental and physical properties, which prevents reducibility.

Another fundamental difference between personal explanation and scientific explanation is to be sought in the element of 'intention.' Intention can be interpreted as the end or final cause among Aristotle's Four Causes. Intention and purpose are the prerequisites of personal explanation. In the example of killing another person, if we ignore the killer's intention, we have provided almost no persuasive explanation of the main event. Suppose all the scientific evidence, including the fingerprint of the murderer, the type of gun, the shooting distance, and so on, are available to the judge. However, he has no idea what the murderer's intention was. Then this homicide will be no different to him than the case of someone killed in a car crash or on the battlefield. Scientific reasons and evidence do not provide a complete (and convincing) explanation of this phenomenon.

Nonetheless, the end and final cause are not included in a scientific explanation. Therefore, it is generally said that the final cause has no place in modern science. Natural scientists and naturalist philosophers argue that having a final and teleological explanation is the concern of art and craftsmanship, but natural sciences that deal with unconscious nature are free from final cause ${ }^{13}[25$, p. 11].

Due to the abovementioned differences between the components of personal explanation and scientific explanation ${ }^{14}$, we can argue in favor of the fundamental distinction between these two types of explanation and the irreducibility of personal explanation to scientific explanation. There are also independent arguments in favor of the irreducibility of mental properties to physical properties, most famous of which is the 'multiple realizability'. According to this argument, a mental property (e. g., pain) may correspond to several physical properties (e. g., C-fiber firing in one organism and D-fiber firing in another

${ }^{13}$ It should be noted that rejection of teleology in science means negation of a priori purpose and not negation of function. Modern science accepts functional explanations. This is particularly important in evolutionary biology. In the theory of evolution, one the one hand, it is questioned whether the world serves a purpose, but on the other hand, every organism moves towards more adaptation according to a purposeful pattern. Purposefulness which is accepted in the theory of evolution is called 'telenaturalism' in which purpose serves a more descriptive rather than explanatory role. (For further study in this area, see [24].)

${ }^{14}$ And other differences such as 'privileged access' to mental states and 'subjectivity', all of which can be found in the literature on philosophy of mind but are not discussed in the present article. 
organism). In short, this argument states that a mental property cannot be considered as simply corresponding to a specific physical property [26, p. 131]. This argument is a turning point in philosophers' refrain from physical reductionism [26, p. 129]. Implication and generalization of this argument also includes the irreducibility of special sciences (such as economics, sociology, psychology, and biology) to physics. In fact, multiple realizability states that there are no strict laws to link a mental property, such as the elements mentioned in the definition of personal explanation (including belief and desire), to a physical property [27].

Nevertheless, regardless of multiple realizability, my argument is that assuming reductionism, we have no reason to admit purposefulness of human actions as well as a moral responsibility. As we saw in the previous section, scientific explanation embraces the principle of explanatory closure and does not go beyond the limits of natural (temporalspatial) issues to explain phenomena. Thus, by accepting reductionism, we are forced to reduce things such as desire and belief to objective elements such as brain interactions. The direct implication of such reduction is that there is no preferential criterion that distinguishes one person's action from another person's action (remember the example of killing a person). Hence, reductionism not only renders man's actions devoid of meaning but also ignores his moral responsibility, which could impose significant costs. Therefore, due to this outcome's inconsistency with our intuition and unreasonableness to accept these costs, the less costly way is to abandon reductionism - what many philosophers (even naturalist philosophers) have preferred to do.

In summation, in the third section of this article, I presented an argument to demonstrate that naturalism is incapable of providing a complete explanation. In the last two parts, I tried to give reasons in favor of the 3 and 4 premises of the argument. Premise 5 of the argument, which stated that 'personal explanation could not be explained by naturalism, is a result of combining premise 4 and the definition of naturalism. In fact, if a personal explanation cannot be reduced to a scientific explanation, based on the definition of methodological naturalism, the personal explanation will be inconsistent with naturalism. Premise 6, which is the conclusion of the argument, results from combining premise 3 and premise 5 .

\section{Conclusion}

The present article explains how the naturalistic approach deals with ultimate questions. By admitting the scientific method as the sole source of gaining reliable knowledge and accepting its limitations, naturalism cannot have an anti-realistic view on ultimate questions because these questions' answers shed light on scientific theories. Secondly, a naturalist cannot go beyond the scientific method's framework and take an anti-naturalistic approach. However, answering these questions requires a complete explanation, which does not leave any factor or remains of any element even in higher explanandum levels.

Since complete explanation includes personal explanation, naturalism can provide a complete explanation only if it also includes personal explanation or if personal explanations are reduced to scientific explanations. Nevertheless, personal explanation contains mental properties such as belief and desire, which are prevented from being reduced to scientific explanation. Consequently, naturalism does not possess sufficient explanatory power to provide a complete explanation and, as a result, cannot answer ultimate questions. 


\section{References}

1. Kim, J. (2003), The American Origins of Philosophical Naturalism, Journal of Philosophical Research, vol. 28 , pp. 83-98.

2. Sellars, R. W. (1927), Why Naturalism and Not Materialism, Philosophical Review, vol. 36, pp. $216-$ 225.

3. Haught, J. (2006), Is Nature Enough? Meaning and Truth in the Age of Science, New York: Cambridge University Press. 355.

4. Popper, K. (1978), Natural Selection and the Emergence of Mind, Dialectica, vol. 32, no. 3-4, pp. 339

5. Baeyer, H. C. von (2005), Information: The New Language of Science, Cambridge, MA: Harvard University Press.

6. McGrath, A. (2015), The Big Question: Why We Can't Stop Talking About Science, Faith and God, New York: St. Martin's Press.

7. Hawking, S. W. (2001), The Universe in a Nutshell, New York: Bantam books.

8. Churchland, P. (1981), Eliminative Materialism and the Propositional Attitudes, The Journal of Philosophy, vol. 78, pp. 67-90.

9. Wimsatt, W. and Sarkar, S. (2006), Reductionism, In S. Sarkar and J.Pfeifer (eds), The Philosophy of Science: An Encyclopedia, New York: Routledge, pp. 696-703.

10. Putnam, H. (2010), Philosophy of Logic, New York: Routledge.

11. Price, H., (1997), Naturalism and the Fate of the M-Worlds, Proceedings of the Aristotelian Society, vol. 71, pp. 247-267.

12. Eccles, J. (1994), How the SELF Controls Its BRAIN, Berlin: Springer-Verlag.

13. Ravenscroft, I. (2005), Philosophy of Mind: A Beginner's Guide, Oxford: Oxford University Press.

14. Montero, B. (2003), Varieties of Causal Closure, in Walter, S., Physicalism and Mental Causation: The Metaphysics of Mind and Action, Exeter: Imprint Academic, pp. 173-191.

15. Swinburne, R. (2004), The Existence of God, Oxford: Oxford University Press.

16. Rosenberg, A. (2005), Philosophy of Science: A Contemporary Introduction, London: Routledge Taylor \& Francis group.

17. Ladyman, J. (2002), Understanding Philosophy of Science, London: Routledge Taylor \& Francis Group.

18. Garfield, E., (1986), The Metaphor-Science Connection, Essays of an Information Scientist, vol. 9, pp. 3-10.

19. Cartwright, N., (1983), How the Laws of Physics Lie, Oxford Scholarship Online: November 2003. Available at: https://oxford.universitypressscholarship.com/view/10.1093/0198247044.001.0001/ acprof-9780198247043 (accessed: 01.09.2020).

20. Polkinghorne, J., (2000), The Metaphysics of Divine Action, in Russell, R., Murphy, N. and Peacocke, A., Chaos and Complexity: Scientific Perspectives on Divine Action/Vatican observatory, Notre Dame, IN: University of Notre Dame Press, pp. 146-156.

21. Swinburne, R., (2010), God as the Simplest Explanation of the Universe, European Journal of Philosophy of Religion, no. 2, pp. 3-24.

22. Dennett, D. (1986), Content and Consciousness, London: Routledge and Kegan Paul.

23. Davidson, D. (2002), Mental Events, in Chalmers, D., Philosophy of Mind: Classical and Contemporary Readings, Oxford: Oxford University Press, pp. 116-126.

24. Allen, C. A. (2019, Spring), Teleological Notions in Biology, in Zalta, E. N. (ed.), The Stanford Encyclopedia of Philosophy. Available at: https://plato.stanford.edu/archives/spr2019/entries/teleology-biology (accessed: 01.09.2020).

25. Ellis, B. (2002), The Philosophy of Nature, Chesham: Acumen.

26. Kim, J. (2011), Philosophy of Mind, $3^{\text {rd }}$ ed., Boulder: Westview Press.

27. Fodor, J. (1974), Special Sciences (Or: The Disunity of Science as a Working Hypothesis), Synthese, vol. 28 , no. 2, pp. 97-115.

Received: September 16, 2020 Accepted: March 10, 2021

Author's information:

Javad Darvish Aghajani - Postgraduate Student; javad.darvish83@student.sharif.edu, javad.darvish@gmail.com 


\title{
Оценка объясняющей силы натурализма в решении важнейших вопросов
}

\author{
Дж. Дарвиш Агаджани
}

Технологический университет им. Шарифа,

Исламская Республика Иран, 11365-11155, Тегеран, ул. Азади

Для цитирования: Darvish Aghajani J. Assessing the explanatory power of naturalism in addressing ultimate questions // Вестник Санкт-Петербургского университета. Философия и конфликтология. 2021. Т. 37. Вып. 2. С. 217-228. https://doi.org/10.21638/spbu17.2021.203

Обычно ученые-натуралисты свою задачу видят лишь в том, чтобы объяснять природные явления. Когда же философы спрашивают об условиях, в силу которых объяснения, данные учеными, являются истинными, то они, по сути, задают предельный вопрос - в том смысле, в котором писал об этом Карл Поппер. Чтобы ответить на этот вопрос, необходимо учесть все моменты и важные факторы. Другими словами, при объяснении явления на любом уровне этого объяснения не должно оставаться ничего неучтенного. Эти требования могут быть выполнены посредством исчерпывающего объяснения. В данной статье при помощи указания на теоретическую нагруженность опыта, невыводимость теории из опыта и роль моделей и метафор в создании научной теории показано, что исчерпывающее объяснение включает в себя как научное, так и субъективное объяснение. Субъективное объяснение содержит ментальные компоненты, такие как убеждения, желания и намерения, которые не сводятся к физическим характеристикам. Следовательно, придерживаясь научных методов, мы будем избегать субъективного объяснения. Таким образом, в статье доказывается, что, во-первых, субъективное объяснение не сводится к научному объяснению; во-вторых, субъективное объяснение необходимо для получения исчерпывающего объяснения; в-третьих, (методологические) натуралисты утверждают, что окончательное суждение о том, что является естественным и неестественным, возможно только путем научного исследования; наконец, принятие этих трех посылок влечет за собой вывод о том, что натуралисты неспособны ответить на предельные вопросы.

Ключевые слова: главный вопрос, полное объяснение, натурализм, личное объяснение, редукционизм.

Статья поступила в редакцию 16 сентября 2020 г;; рекомендована в печать 10 марта 2021 г.

Контактная информация:

Дарвиш Агаждани Джавад - докторант; javad.darvish83@student.sharif.edu, javad.darvish@gmail.com 